Article

\title{
The Preparation Process, Microstructure and Properties of Cellular TiC-High Mn Steel-Bonded Carbide
}

\author{
Guoping Li ${ }^{1,2}$, Haojun Zhou ${ }^{1}$, Hao Yang ${ }^{1}$, Mingchu Huang ${ }^{1}$, Yingbiao Peng ${ }^{3, *}$ and \\ Fenghua Luo ${ }^{1, *(\mathbb{D})}$ \\ 1 State Key Laboratory of Powder Metallurgy, Central South University, Changsha 410083, China; \\ guopingli@csu.edu.cn (G.L.); zhouhaojunlife@163.com (H.Z.); yanghaoicsy@163.com (H.Y.); \\ h13657483787@163.com (M.H.) \\ 2 Laiwu Vocational and Technical College, Jinan 271100, Shandong, China \\ 3 College of Metallurgical and Materials Engineering, Hunan University of Technology, Zhuzhou 412008, \\ Hunan, China \\ * Correspondence: pengyingbiao1987@163.com (Y.P.); fenghualuo@csu.edu.cn (F.L.); \\ Tel.: +86-159-731-345-26 (Y.P.); +86-135-741-808-28 (F.L.)
}

Received: 13 January 2020; Accepted: 5 February 2020; Published: 7 February 2020

\begin{abstract}
TiC-high Mn steel-bonded carbide with a cellular structure was designed and fabricated by powder metallurgy techniques using coarse and fine TiC particles as the hard phase. This preparation process of the alloy was designed carefully and optimized. The microstructure of the alloy was observed using a scanning electron microscope. The results show that there are two types of microstructures observed in this $\mathrm{TiC}$ steel-bonded carbide: the coarse-grained TiC structure and fine-grained $\mathrm{TiC}$ structure. The transverse rupture strength and impact toughness of the alloy reach maximum values $2231 \mathrm{MPa}$ and $12.87 \mathrm{~J} / \mathrm{cm}^{2}$, respectively, when the starting weight ratio of MP-A (containing coarse TiC particles) to MP-B (containing fine TiC particles) is 60:40. Hence, this study serves as a feasible and economical example to prepare a high-strength and high-toughness TiC-high Mn steel-bonded carbide with little production cost increase.
\end{abstract}

Keywords: TiC; steel-bonded carbide; cellular structure; high Mn steel binder

\section{Introduction}

Steel-bonded carbide is a new engineering material prepared according to conventional powder metallurgical techniques using $\mathrm{WC}$ and/or TiC as the hard phase and steel as the metallic binder [1,2]. Due to combining high hardness, good wear resistance, excellent oxidation resistant, superior chemical stability of the hard phase, and high toughness and suitable strength of the metallic binder, steel-bonded carbide is used in multiple applications. These applications include wear-resistant parts, extrusion dies and punches, high-speed milling, surface finishing operations, forming tools, and carbon and stainless steel machining [3-7]. Among all the TiC steel-bonded carbides, TiC-high Mn steel-bonded carbide is one of the most successful applications in oil production, mine exploration, coal mining and cement production [8,9]. TiC-high Mn steel-bonded carbide and high Mn steel matrix are cast into a whole composite part. Additionally, the chemical composition of the high Mn steel matrix is the same as the metallic binder of TiC-high Mn steel-bonded carbide. After heat treatment, the microstructure of binder phase in TiC steel-bonded carbide changes into austenite which exhibits a good ductility and toughness. Due to the work-hardening effect of high $\mathrm{Mn}$ steel, the binder microstructure of TiC steel-bonded carbide changes into martensite when the composite part is impacted strongly, making it hard and wear-resistant. This phase transformation of the high Mn steel matrix and the TiC steel-bonded carbide 
is synchronous in improving wear-resistance and prolonging the working life of the composite casting. Therefore, this composite casting is widely applicable in situations with strong impact and vibration.

A prominent disadvantage of TiC- and/or TiCN-based cermets, including TiC steel-bonded carbide, is their brittleness due to the poor wettability of the metallic binder on the hard phase. This leads to the reduced toughness and moderate strength of $\mathrm{TiC}$ steel-bonded carbide compared to tungsten cemented carbide and WC steel-bonded carbide, thereby limiting its applications. Hence, it is crucial to improve the wettability between the binder on the hard phase in order to increase the phase interface bonding strength of the cermets. Studies have confirmed that Mo [10-14], $\mathrm{Mo}_{2} \mathrm{C}$ [14-19], WC [15,18,20-23], $\mathrm{TaC}[15,17,19], \mathrm{NbC}[19]$, and $\mathrm{ZrC}[24]$ can improve the wettability of the metallic binderon the hard phase, refine the hard phase, and modify the mechanical properties of the cermets.

Despite implementing these conditions, the strength and toughness of TiC-based cermets should be further improved to widen their applications. Particularly, since TiC-high Mn steel-bonded carbide is mainly applied in strong impact working conditions, its strength and toughness should be further increased. Previously published results from the author have shown that using Fe-Mo-Cr, Fe-Mo pre-alloyed powders as the binders significantly improved the transverse rupture strength and impact toughness of TiC-high Mn steel-bonded carbide [4,25]. In the fields of geology, rock drilling and other wear- and impact-resistant conditions, it has confirmed that a dual composite WC-Co and a hybrid cemented carbide composite were applied which show excellent toughness under severe shock conditions $[26,27]$ and these previous reports inspired this study. Moreover, research results from the author have shown that using Fe-Mo-Cr, Fe-Mo pre-alloyed powders as the binder provides more variable and selectable parameters to control and modify the mechanical properties of TiC-based cermets $[4,25]$; the variable and selectable parameters include the alloying elements and its amount, particle size, et al of the pre-alloyed powders which can offset some inconveniences and uncertainties during the preparation of adual composite WC-Co and a hybrid cemented carbide composite. Thus, it can be seen that none of the literature relates to information on the preparation, microstructure and properties of a cellular TiC-high Mn steel-bonded carbide. Hence, this study attempts to fill this research gap.

\section{Research Method and Preparation of Materials}

Two types of TiC particles, namely coarse and fine $\mathrm{TiC}$ particles, were chosen as ceramic particles for this study, and the TiC fisher sizes were 3.1-3.3 $\mu \mathrm{m}$ and $0.8-1.5 \mu \mathrm{m}$, respectively. The main characteristics of the raw powders are listed in Table 1. Figure 1 shows the SEM morphology of the two types of TiC particles.

Table 1. Main characteristics of the raw powders in the study.

\begin{tabular}{|c|c|c|c|c|}
\hline Powders & $\begin{array}{l}\text { Particle Size } \\
\qquad(\mu \mathrm{m})\end{array}$ & $\begin{array}{l}\text { Purity } \\
\text { (wt.\%) }\end{array}$ & $\begin{array}{l}\text { Oxygen } \\
\text { (wt.\%) }\end{array}$ & Manufacturer \\
\hline Coarse TiC & $3.1-3.3^{\text {(1) }}$ & $\geq 99.5$ & $\leq 0.25$ & \multirow{2}{*}{$\begin{array}{l}\text { Zhuzhou Cemented Carbide Group Co., } \\
\text { Ltd., China }\end{array}$} \\
\hline Fine TiC & $0.8-1.5^{(1)}$ & $\geq 99.4$ & $\leq 0.28$ & \\
\hline $\mathrm{Ni}$ & 43 & $\geq 99.8$ & $<0.12$ & $\begin{array}{c}\text { Shanghai Xtnami Science \& Technology } \\
\text { Co., Ltd., China }\end{array}$ \\
\hline FeMn81.4 & 74 & $\geq 99.5^{(2)}$ & $<0.15$ & $\begin{array}{c}\text { Jinzhou Honda New Material Co., Ltd., } \\
\text { China }\end{array}$ \\
\hline Graphite & 30 & $\geq 99.8$ & $<0.05$ & $\begin{array}{l}\text { Qingdao Baichuan Graphite Co., Ltd., } \\
\text { China }\end{array}$ \\
\hline $\mathrm{Fe}-1.5 \mathrm{Mo}$ & 74 & $\geq 99.5^{(3)}$ & $<0.28$ & $\begin{array}{l}\text { Laiwu Iron and Steel Group Powder, } \\
\text { Metallurgy Co., Ltd., China }\end{array}$ \\
\hline $\mathrm{Fe}-4.5 \mathrm{Mo}-3.75 \mathrm{Cr}-0.7 \mathrm{C}$ & 147 & $\geq 99.0^{(4)}$ & $<0.30$ & Own Manufacturing \\
\hline
\end{tabular}

(1) Fisher particle size; (2) The total components of Fe and $\mathrm{Mn}$; (3) The total components of Fe and Mo; (4) The total components of $\mathrm{Fe}, \mathrm{Mo}, \mathrm{Cr}$ and $\mathrm{C}$. 

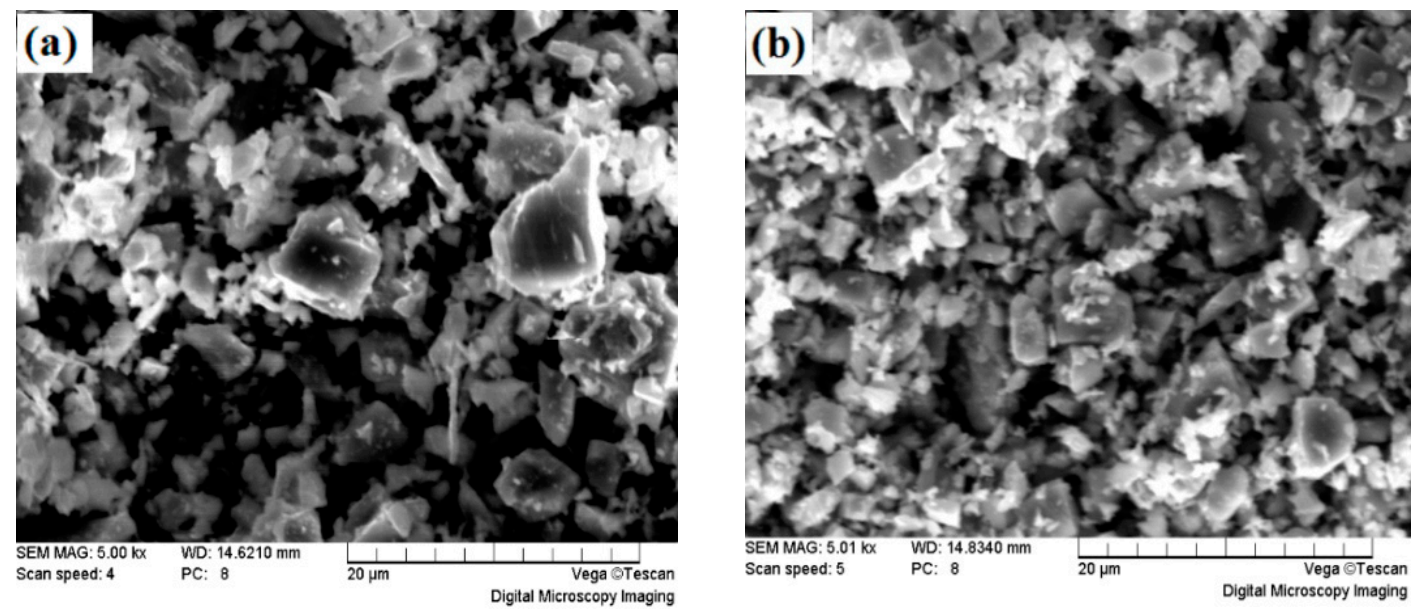

Figure 1. SEM morphology of TiC particles, (a) coarse TiC, (b) fine TiC.

The main purpose of this study was to obtain a type of inhomogeneous TiC-high Mn steel-bonded carbide deliberately. Within its microstructure, there is an aggregation area of fine-grained TiC, i.e., cellular microstructure. Therefore, in the process of alloy design, mixing and sintering, effective measures and steps should be taken to prevent the coarsening of fine $\mathrm{TiC}$ particles.

Nickel, ferromanganese, graphitic carbon and pre-alloyed iron powders are used as bonding phases. The pre-alloyed iron powders, prepared by water atomization method, are Fe-1.5Mo (200 mesh, $\leq 74 \mu \mathrm{m})$ and Fe-4.5Mo-3.75Cr-0.7C (100 mesh, $\leq 154 \mu \mathrm{m})$, respectively. Among them, Fe-1.5Mo pre-alloyed iron powder is used as the bonding phase of coarse $\mathrm{TiC}$ powder, while Fe-4.5Mo-3.75Cr-0.7C pre-alloyed iron powder is used as the bonding phase of fine TiC powder. Figure 2 shows the SEM morphology of the pre-alloyed iron powders, Figure 2a refers to the Fe-1.5Mo pre-alloyed powder, and its particle size is $25 \sim 67 \mu \mathrm{m}$; while Figure $2 \mathrm{~b}$ refers to the Fe-4.5Mo-3.75Cr-0.7C pre-alloyed iron powder, and its particle size is $100 \sim 210 \mu \mathrm{m}$.
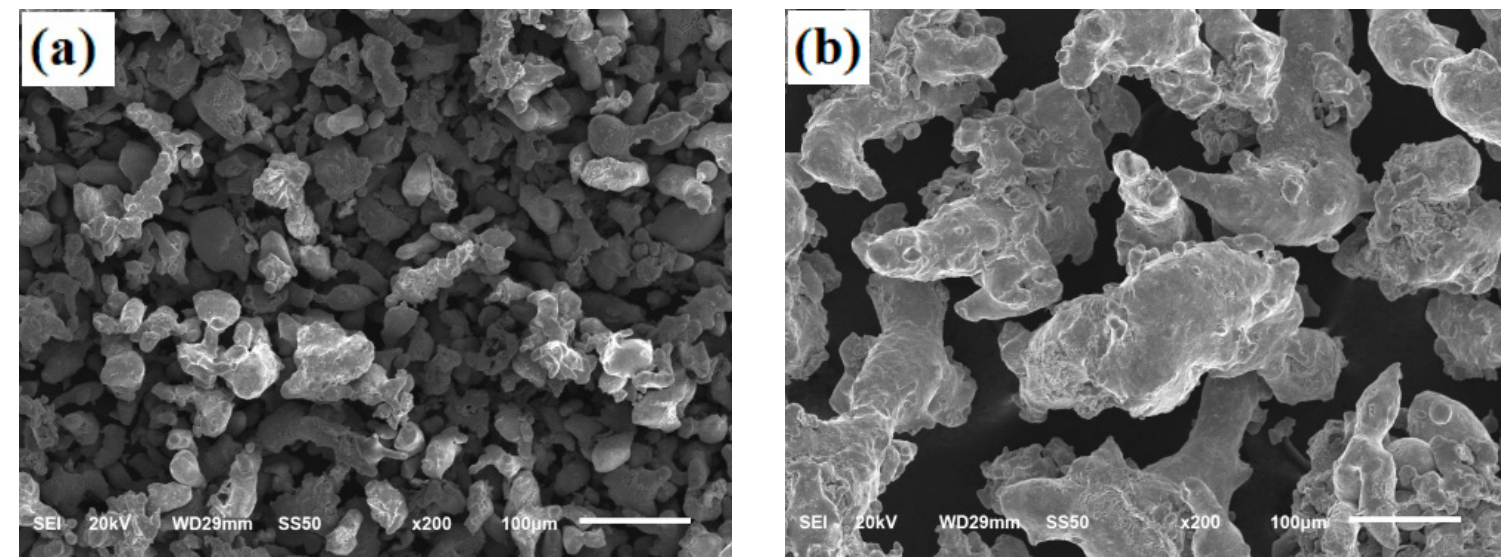

Figure 2. SEM morphology of pre-alloyed iron powders, (a) Fe-1.5Mo, (b) Fe-3.0Mo-3.75Cr-0.7C.

The raw powders are weighed and mixed to form two kinds of mixed powder. The composition and proportions of ingredients of the two kinds of mixed powder are listed in Table 2. The mixed powder containing coarse TiC particles was marked as MP-A (mixed powder A), while the mixed powder containing fine TiC particles was marked as MP-B (mixed powder B). 
Table 2. Composition and proportions of ingredients of MP-A and MP-B (wt.\%).

\begin{tabular}{ccccccc}
\hline Mixed Powder & TiC & Ni & Mo & Mn & C & Pre-Alloyed Iron Powder \\
\hline MP-A & 50 & 2.25 & 0.6 & 7.0 & 0.7 & Bal. (Fe-1.5Mo) \\
MP-B & 46 & 2.25 & - & 7.0 & 0.41 & Bal. (Fe-4.5Mo-3.75Cr-0.7C) \\
\hline
\end{tabular}

The design of MP-A is to form the coarse-grained TiC area. Hence, fine-grained Fe-1.5Mo pre-alloy powder is selected as the bonding phase to activate sintering and a lower grinding ball to powder weight ratio selected to avoid crushing and refining TiC particles excessively. MP-B is designed to form the fine-grained $\mathrm{TiC}$ area, so coarse-grained $\mathrm{Fe}-4.5 \mathrm{Mo}-3.75 \mathrm{Cr}-0.7 \mathrm{C}$ pre-alloy powder is selected as the bonding phase to repress the growth of $\mathrm{TiC}$ grains and a higher grinding ball to powder weight ratio selected to enhance the milling of $\mathrm{TiC}$ particles as finely as possible. Additionally, $\mathrm{Cr}$ element is added in the MP-B system because $\mathrm{Cr}$ can reduce the eutectic temperature of the alloy and influence the particle shape, particle size of ceramic phase in conjunction with Mo and/or $\mathrm{C}$ to modify the properties of TiC steel-bonded carbide [4].

After weighing their ingredients, MP-A and MP-B were mixed in a V-type mixer (Wuxi Xinbang Manufacturing of Powder Equipment Co., Ltd., Wuxi, China) for $120 \mathrm{~min}$ and then ball-milled in a planetary ball mill (Changsha Tianchuang Powder Technology Co., Ltd., Changsha, China) bathed in ethanol for $24 \mathrm{~h}$ at a rotation speed of $220 \mathrm{rpm}$. A stainless steel ball was selected as the grinder. To avoid excessive grind of coarse TiC particles, the grinding ball to powder weight ratio was 3:1 for MP-Awhile that of MP-B was 6:1 to mill fine TiC particles as much as possible. The milling time was similar for both materials for operational convenience and to guarantee uniformity of MP-A and MP-B, respectively.

The above wet grinding slurry was dried in a vacuum oven (Shanghai Dengsheng Instrument Manufacturing Co., Ltd., Shanghai, China) at $70^{\circ} \mathrm{C}$ for $8 \mathrm{~h}$ when the milling processes were completed. Subsequently, $4 \mathrm{wt} . \%$ styrene-butadiene rubber (SBR) (Shouguang city fat special petroleum products co. Ltd., Weifang, China) was added in both mixed powders as a forming agent. The rubber was dissolved in gasoline to form a rubber-gasoline solution with a concentration of $10.83 \%$, which can guarantee a uniform distribution of rubber in the powders. Both powders, MP-A and MP-B, were dried in a vacuum oven at $80^{\circ} \mathrm{C}$ for $12 \mathrm{~h}$ to remove the gasoline and then were pressed into columnar green compacts $\left(\Phi 20 \times 20 \mathrm{~mm}^{3}\right)$ at a pressure of $30 \mathrm{MPa}$. The green compacts were crushed with a crushing screen to get 60 mesh $(\leq 250 \mu \mathrm{m})$ pre-granulated mixed powder. This process was named the block granulation method. In this process, the amount of rubber additive was higher than that of conventional TiC steel-bonded carbide, so the strength of the pre-granulated mixed powder was increased to prevent disintegration in the subsequent remixing process, which facilitated the formation of a honeycomb structure in the alloy.

The two types of pre-granulated mixed powders, MP-A and MP-B, were remixed according to the proportion listed in Table 3 to prepare four experimental samples.

Table 3. Relationship of experimental samples using MP-A and MP-B (wt.\%).

\begin{tabular}{ccccc}
\hline Sample & \#1 & \#2 & \#3 & \#4 \\
MP-A & 80 & 60 & 40 & 20 \\
MP-B & 20 & 40 & 60 & 80 \\
\hline
\end{tabular}

MP-A and MP-B were weighed according to the proportion of Table 3 and remixed in a V-type mixer for $120 \mathrm{~min}$, then $2 \mathrm{wt}$.\% rubber (SBR) was added in the powder mixture. The adding mode and operation are the same as the former process and the gasoline added was removed in a vacuum oven at $80{ }^{\circ} \mathrm{C}$ for $12 \mathrm{~h}$. The dried powder mixture was pressed into columnar compacts $\left(\Phi 20 \times 20 \mathrm{~mm}^{3}\right)$ at a pressure of $15 \mathrm{MPa}$ and then crushed with a crushing screen to obtain 20 mesh $(\leq 830 \mu \mathrm{m})$ re-granulated mixed powder. This re-granulation operation is aimed at ensuring the uniform distribution of MP-A 
and MP-B in the re-granulated particles. The re-granulated powder was pressed into the columnar green compacts $\left(\Phi 20 \times 60 \mathrm{~mm}^{3}\right)$ under a uniaxial pressure of $200 \mathrm{MPa}$. Subsequently, the columnar green compacts were vacuum-sintered at $1420{ }^{\circ} \mathrm{C}$ for $60 \mathrm{~min}$ to obtain the bulk samples.

Figure 3 represents the integrated dewaxing and sintering curve of the TiC-high Mn steel bonded carbide in the study.

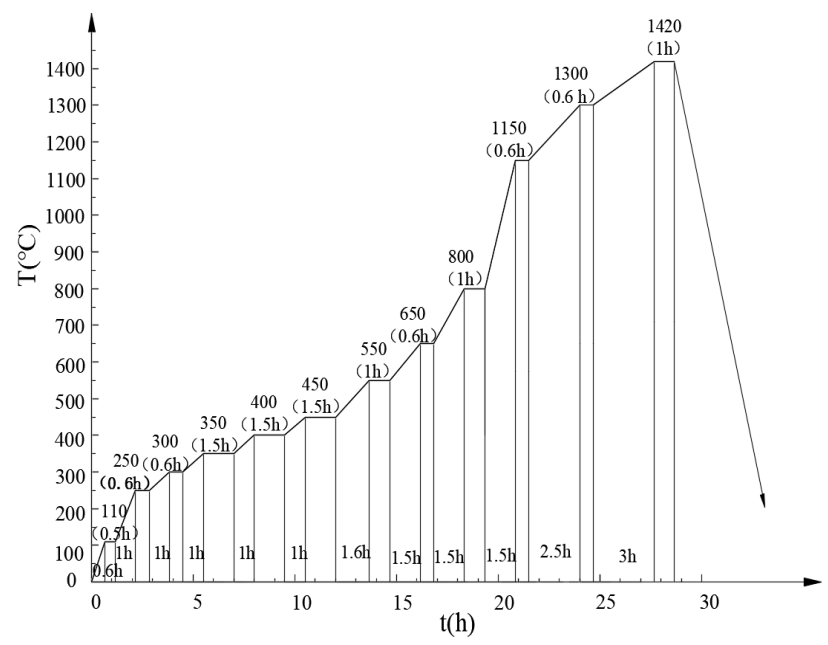

Figure 3. The integrated dewaxing and sintering curve of the alloy.

As shown in Figure 3, in the dewaxing stage $\left(250-650^{\circ} \mathrm{C}\right)$, multiple insulation stages were set up to dewax the forming agent completely for its perfect viscidity and increased content. Herein, two important insulation stages were observed, the first at $1150{ }^{\circ} \mathrm{C}$ where the carbon reduced the inevitable small amount of metallic oxides in the Fe powder, and the second at $1300^{\circ} \mathrm{C}$, where the metallic binder became molten or semi-molten. In the latter stage of high-temperature insulation, the flow of liquid adhesive along the ceramic particle space is promoted in order to effectively separate the ceramic particles from each other and thus, facilitate the formation of a TiC "skeleton". These sintering processes are designed especially for TiC-based cermets using Fe-Mo and Fe-Mo-Cr pre alloyed powders as the binders [4]. Table 4 .

The preparation processes of the cellular TiC-high Mn steel-bonded carbide are summarized in

Table 4. Preparation processes of the cellular TiC-high Mn steel-bonded carbide.

\begin{tabular}{ccc}
\hline Procedure & Process Name & Main Contents and Parameters \\
\hline 1 & Weighing and mixing & $\begin{array}{c}\text { Weighing the ingredients of MP-A and MP-B, and mixing } \\
\text { for } 120 \text { min. }\end{array}$ \\
\hline 2 & Wet-milling & $\begin{array}{c}\text { Ball to powder weight ratio: 3:1 for MP-A, 6:1 for MP-B; } \\
\text { milling time: } 24 \text { h; protective medium in milling: ethanol }\end{array}$ \\
\hline 3 & Pre-granulation & Adding 4 wt. $\%$ rubber; block granulation method; 60 mesh \\
\hline 4 & Weighing and mixing & Weighing MP-A and MP-B; remixing for 120 min \\
\hline 5 & Re-granulation & Adding 2 wt. $\%$ rubber; block granulation method; 20 mesh \\
\hline 6 & Pressing of green compacts & 200 MPa uniaxial pressing; $\Phi 20 \times 60$ mm ${ }^{3}$ \\
\hline 7 & Sintering & Sintering temperature: $1420{ }^{\circ} \mathrm{C}$ for $60 \mathrm{~min}^{2}$ \\
\hline
\end{tabular}

Finally, the bulk specimens were machined by wire-electrode cutting for the test samples. The geometrical size of the test samples for hardness and SEM microstructure observation is $10 \mathrm{~mm} \times 10 \mathrm{~mm} \times 15 \mathrm{~mm}$, and the cross section of $10 \mathrm{~mm} \times 10 \mathrm{~mm}$ for test is prepared with the standards of metallographic observation. The Rockwell hardness of the sintered cellular TiC-high Mn 
steel-bonded carbide was measured using an HR-150B Rockwell hardness tester (Laizhou Huayin Instruments Co., Ltd., Yantai, China) under a load of $60 \mathrm{~kg}$. The transverse rupture strength (TRS) of the alloy was measured by a WDW-100E universal material testing machine (Jinan Test Machine Co., Ltd., Jinan, China) with a specimen size of $5 \mathrm{~mm} \times 5 \mathrm{~mm} \times 35 \mathrm{~mm}$, a span distance of $20 \mathrm{~mm}$, and a cross head velocity of $0.5 \mathrm{~mm} / \mathrm{min}$. The impact toughness (IM) test was performed using a JBW impact testing machine (Jinan Shijin Group Ltd., Jinan, China) with a specimen size of $10 \mathrm{~mm} \times 10 \mathrm{~mm} \times 55 \mathrm{~mm}$. The density of the bulk specimens was measured using the Archimedes method and composition analysis was carried out using energy dispersive spectroscopy (EDS). The fracture surface morphology was observed using a SEM in secondary electron (SE) mode. The tunneling electron microscopy lamellae were prepared from the pins using a focused-ion beam (FIB, Fei Czech Republic S.R.O., Hillsboro, OR, USA). A transmission electron microscope (TEM, Fei Czech Republic S.R.O., Hillsboro, OR, USA) was used to investigate the selected area's electron diffraction and microstructural characteristics of particular areas of the cermets.

\section{Results}

Figure 4 shows the SEM images of the experimental samples. These images show that the microstructures of the samples containing MP-A and MP-B are not well distributed. The area marked with the red circles in Figure 4 represents the zone where a concentration of fine TiC particles was observed. Other than the fine TiC particles concentration zone, coarse $\mathrm{TiC}$ particles are the main components of the samples. The special structure of the fine TiC concentration zone is located in coarse TiC particles matrix which looks like a honeycomb, also called a cellular structure.
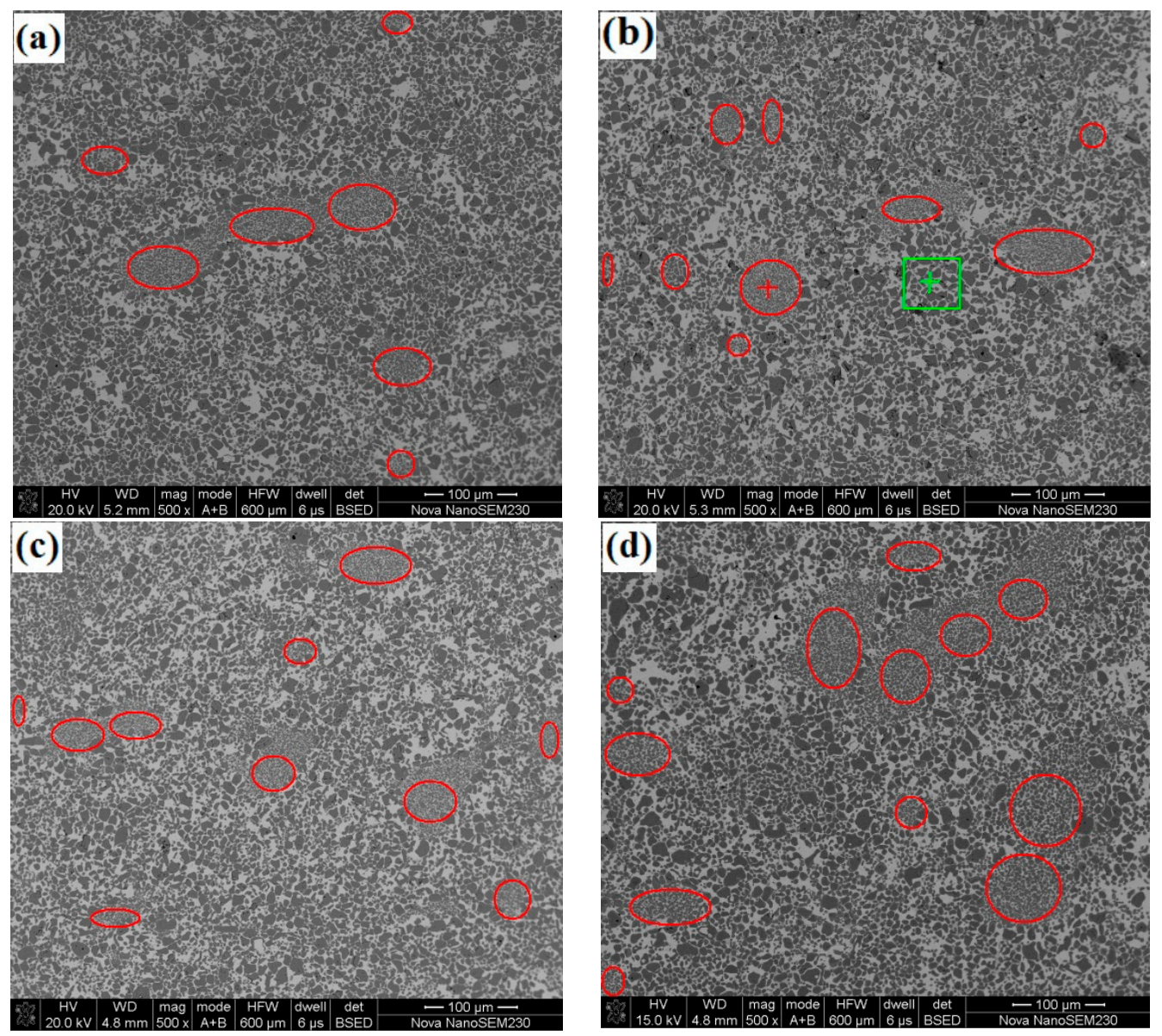

Figure 4. SEM images of the experimental samples, (a)\#1, (b) \#2, (c) \#3, and (d) \#4. 
In order to confirm the chemical composition of fine-grained $\mathrm{TiC}$ zone and coarse-grained $\mathrm{TiC}$ zone, an EDS analysis was conducted. The testing position for fine-grained TiC zone and coarse-grained TiC zone was marked with a red "+" symbol and a green "+" symbol, respectively, as shown in Figure $4 \mathrm{~b}$ (sample \#2). Table 5 shows the EDS analysis results of the fine-grained TiC zone and the coarse-grained TiC zone.

Table 5. EDS analysis result of the fine-grained $\mathrm{TiC}$ zone and coarse-grained $\mathrm{TiC}$ zone.

\begin{tabular}{ccccccccc}
\hline Elements Content, wt.\% & $\mathbf{C}$ & $\mathbf{M o}$ & $\mathbf{T i}$ & $\mathbf{C r}$ & $\mathbf{M n}$ & $\mathbf{F e}$ & $\mathbf{N i}$ & Total \\
\hline Coarse-grained TiC zone & 10.47 & 0.85 & 46.64 & 0.26 & 5.13 & 32.72 & 3.92 & 100 \\
Fine-grained TiC zone & 10.27 & 2.69 & 42.25 & 5.90 & 4.89 & 30.79 & 3.22 & 100 \\
\hline
\end{tabular}

Table 5 shows that $\mathrm{Cr}$ content in the fine-grained $\mathrm{TiC}$ zone is much higher than that of the coarse-grained $\mathrm{TiC}$ zone. Thus, this means that the fine-grained $\mathrm{TiC}$ zone is formed by MP-B, while the coarse-grained TiC zone is formed by MP-A, which is consistent with our design and expectation.

Table 5 also indicates that a deviation exists between the measured and designed value of elements $\mathrm{Mo}, \mathrm{Cr}$, and Ni. The measured Mo content in fine-grained $\mathrm{TiC}$ zone is much higher than that of coarse-grained TiC zone, which indicates that pre-alloying of the Mo element is quite necessary, for example, to form Fe-Mo or Fe-Mo-Cr pre-alloyed powders initially in order to make full use of the improvement effect of Mo element on the cermets.

The content deviation of $\mathrm{Cr}$ and $\mathrm{Ni}$ is attributed to the stainless balls used as the grinders of the planet ball mill because the worn fragments of the grinder are left in the alloy, thus increasing the content of $\mathrm{Cr}$ and Ni. Another possible reason for the deviation is the liquid binder of MP-B, which occurred in advance because of the lower eutectic temperature caused by $\mathrm{Cr}$ and $\mathrm{C}$, seeping into the region of MP-A. The measurement method and instrument accuracy may have also contributed to these discrepancies.

The density of the sintered bulk samples was measured using the Archimedes method, and the relative density is the ratio of actual density to theoretical density, as shown in Table 6. It is noteworthy that the relative density of the samples decreased slightly with the increase of MP-B. One reason is that the surface adsorbed oxygen by fine TiC particle increases with increase in the MP-B. The second probable reason is that $\mathrm{Cr}$ content increases with increase in the MP-B and reduces the sinterability of the alloy because of the strong affinity of $\mathrm{Cr}$ with oxygen.

Table 6. Relative density of thecellular TiC-high Mn steel-bonded carbides.

\begin{tabular}{ccccc}
\hline Samples & \#1 & \#2 & \#3 & \#4 \\
\hline Relative density (\%) & 98.57 & 98.51 & 98.48 & 98.33 \\
\hline
\end{tabular}

Table 7 lists the mechanical properties of TiC-high Mn steel-bonded carbide, including hardness, transverse rupture strength (TRS) and impact toughness (IM).

Table 7. Properties of the cellular TiC-high Mn steel-bonded carbides.

\begin{tabular}{cccc}
\hline Sample & Hardness (HRC) & TRS (MPa) & IM $\left(\mathbf{J} / \mathbf{c m}^{\mathbf{2}}\right)$ \\
\hline$\# 1$ & 63.2 & 2078 & 9.17 \\
$\# 2$ & 64.3 & 2231 & 12.87 \\
$\# 3$ & 64.1 & 2206 & 12.11 \\
$\# 4$ & 62.7 & 2027 & 9.05 \\
\hline
\end{tabular}

Table 7 shows that the hardness of the samples increases initially and then decreases with the growth of the cellular structure. Meanwhile, the hardness of sample \#2 reached an ideal maximum 
value 64.3 HRC. The transverse rupture strength (TRS) and impact toughness (IM) of the \#2 alloy also reached the maximum values of $2231 \mathrm{MPa}$ and $12.87 \mathrm{~J} / \mathrm{cm}^{2}$, respectively.

\section{Discussion}

The key process for forming the cellular TiC-high Mn steel-bonded carbide is aimed at preserving the primary characteristics of fine $\mathrm{TiC}$ particles. In addition to sintering temperature, which is the most important parameter and should thus be selected carefully, many other parameters were also selected carefully to ensure the formation of cellular structures. Fe-1.5Mo pre-alloyed powder is used as the binder for MP-A to guarantee uniform growth of the coarse TiC particles and to offset its excessive growth at a high sintering temperature. Pure Mo powder is also added to achieve the total designed Mo content of the alloy, which is expected to promote the growth of coarse TiC particles given that it is more active than that of Fe-Mo pre-alloyed powder. The final TiC particle size produced by MP-A depends on the initial TiC particle size, binder composition and characteristics, ball-milling technology, and sintering technology among others. TiC grain growth is the competitive result of these comprehensive influencing factors.

For MP-B, Fe-4.5Mo-3.75Cr-0.7C pre-alloyed powder is used as the binder to repress grain growth with increasing Mo content. The alloying elements Mo-Cr and Mo-Cr-C have a complex and profound effect on the $\mathrm{TiC}$ grain growth. $\mathrm{Cr}$ and $\mathrm{C}$ decrease the eutectic temperature of the alloy to promote $\mathrm{TiC}$ grain growth. However, Mo and $\mathrm{Cr}$ influence and control the particle size and shape of the TiC grains complexly [4]. Hence, like MP-A, the TiC grain growth behavior of MP-B is also dependent on the comprehensive influencing factors. After this precise design, MP-A and MP-B were mixed and sintered at the same temperature to achieve the different expected goals.

In the re-granulating operation, some granulated $\mathrm{Cr}$-containing MP-B particles may be broken inevitably. The broken small MP-B particles are mixed with or attached to the MP-A granulated particles. The broken small MP-B particles grow to form small size cellular structures; perhaps other smaller MP-B particles disappear and integrate into MP-A completely. Therefore, a small amount of $\mathrm{Cr}$ was found in coarse-grained TiC zone, as shown in Table 6, which strengthens the binder and is beneficial to the properties of the designed cermets.

The areas of cellular structure were calculated using the Image 88 system in Figure 4 . The areas of fine-grained $\mathrm{TiC}$ zones of the four experimental samples were $16.3 \%, 25.4 \%, 34.8 \%$ and $42.1 \%$, respectively. Although the area of the fine-grained TiC zones increases with the addition of MP-B, the increased amount is not equal to the addition of MP-B granulated powder. It is indicated that the granulated MP-B particles were broken in the subsequent remixing, re-granulating, and pressing process. The broken small MP-B particles were integrated with coarse $\mathrm{TiC}$ particles, thus becoming a part of the coarse-grained $\mathrm{TiC}$ zone. Some regions with a small quantity of fine $\mathrm{TiC}$ particles are observed in Figure 4, which is proof of the broken MP-B particles. Additionally, the cellular structure size is evidently not completely consistent with the granulated particle size (60 mesh, $250 \mu \mathrm{m})$. A few cellular structures are larger than the granulated particle and the cellular structure shape is not round or elliptical (Figure 4a,d). Some cellular structures are significantly smaller than the granulated particles and the cellular structure shape is also not round or elliptical (Figure $4 b, c)$. It also shows that it is difficult to preserve the granulated particle size even after adding excessive forming agent in the block granulation preparation process. How to control the cellular structure size, shape, number and its distribution is still a significant problem. However, in any case, this study is a very useful attempt at offering a solution.

The formation of the cellular structure of the alloy is definitely attributed to the initial fine TiC particles, strengthening ball-milling process, binder composition, and so on. Among these factors, binder composition plays an important role in the formation of the cellular structure, because the alloying elements, $\mathrm{Cr}$, Mo, and $\mathrm{C}$ have a significant and complex effect on the sintering process. $\mathrm{Cr}$ is the most important element in the formation of the cellular structure as it reduces the eutectic temperature of the alloy and promote the appearance of liquid metallic binder in the initial stage of sintering. Its 
effect is more obvious when it is combined with the existence of carbon in Fe-Mo-Cr-C pre-alloyed powder. With the improving wettability effect of Mo on the ceramic phase in Fe-Mo-Cr-C pre-alloyed powder, the liquid binder can flow throughout the TiC particles space and effectively separate them from each other during the sintering process. The coalescence grain growth of TiC particles is primarily inhibited and the dissolution-precipitation grain growth is also repressed. Hence, the fine-grained TiC zones form eventually. On the other hand, $\mathrm{Cr}$ is a strong carbide forming element in the formation of $\mathrm{Cr}_{3} \mathrm{C}_{2}$ or compound carbide, and $\mathrm{Cr}_{3} \mathrm{C}_{2}$ is an effective grain growth inhibitor for WC cemented carbide, TiC- and/or TiCN-based cermets. While no $\mathrm{Cr}_{3} \mathrm{C}_{2}$ grain growth inhibitor forms in MP-A powder, the broken MP-B particles provide insufficient $\mathrm{Cr}$ to form $\mathrm{Cr}_{3} \mathrm{C}_{2}$ inhibitor, so the MP-A particles grow a coarse-grained TiC ceramic matrix, merging broken small MP-B particles. In addition, the design of MP-A particles and the preparation process is meant to promote the grain growth of the coarse-grained TiC zone.

However, due to the imperfect preparation process adopted in the study, it is difficult to obtain the inhomogeneous alloy such that the cellular structure distributes among the coarse-grained TiC zones uniformly. Here, the meaning of the inhomogeneous alloy should conclude reasonable number, proper size, perfect shape and good distribution of the cellular structure that can improve the mechanical properties of the cermets. Although the microstructures in Figure $4 b, c$ look more uniform than those in Figure $4 a, d$, they cannot be representative of the overall and actual microstructure of these cermets due to the limited microstructure observation ranges. With the increase of MP-B particles, the uncertainty in the inhomogeneity of the microstructure of the alloys increases, which has negative effects on the mechanical properties. In addition, the change in density may cause the loss of strength and hardness.

Figure 5 shows the impact fracture morphology of Samples \#1 and \#2 observed by SEM. It shows that trans-crystalline rupture is the dominant mode within the coarse-grained $\mathrm{TiC}$ zone and cleavage fracture is observed through some coarse TiC particles, marked with the green symbol " $\square$ ". Trans-granular and inter-granular fractures are found in the fine-grained TiC zones, marked with the red symbol, "O". The binder ductile fracture of the fine-grained TiC zone is a significant contributor to the toughness of the alloy in the crack-penetrating stage [28]. In the fracture stage, the trans-crystalline rupture (coarse and fine $\mathrm{TiC}$ particles) of the alloy was the dominant mechanism in improving the toughness because of the high rigidity of ceramic phase [29]. However, the area with fine-grained TiC broken zones was larger than that with coarse-grained $\mathrm{TiC}$ zones, which confirms that the cellular alloy structure is more important to the impact toughness.
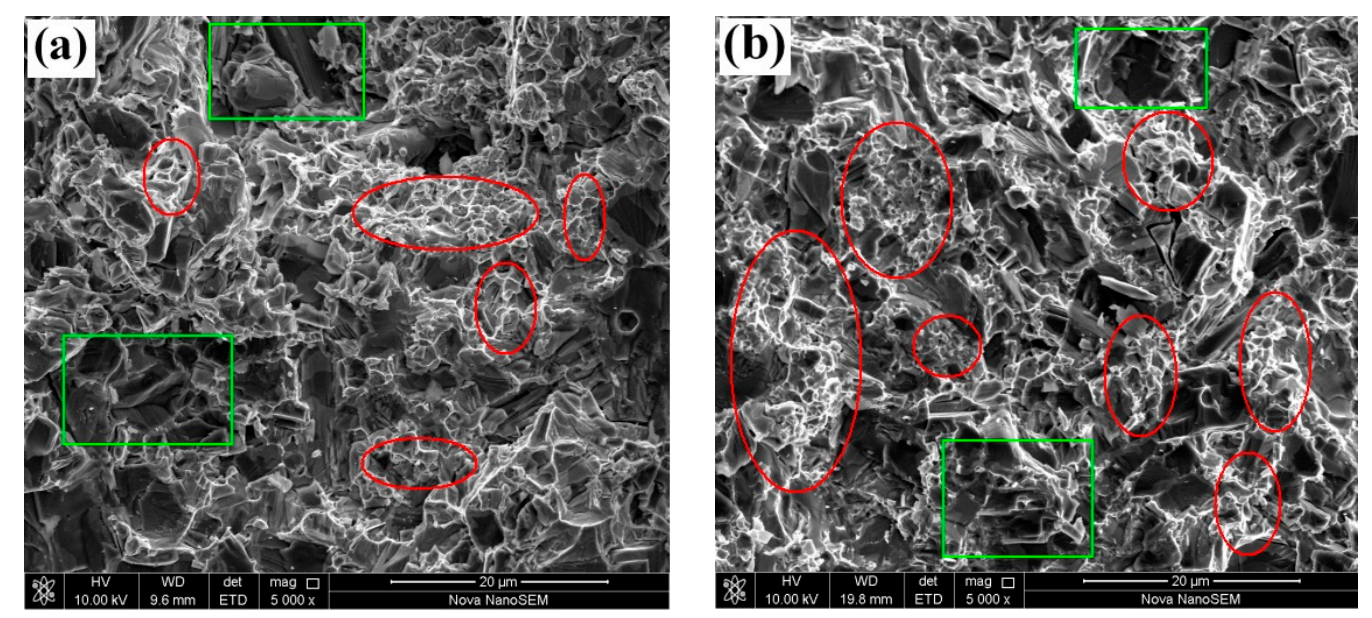

Figure 5. Impact fracture surface morphology of (a) Sample \#1 and (b) Sample \#2.

Some effective attempts at improving toughness for $\mathrm{TiC}$ - and/or TiCN-based cermets are the character modification of the ceramic phase. The toughness of the cermets depends not only on the binder but also on the ceramic phase. It is clear that the hard phase plays a more important role in 
improving the toughness because trans-granular fracture is the dominate mode of TiC steel-bonded carbide. Many studies have shown that the properties of TiC- and TiCN-based cermets with WC additive improved effectively because WC improves the wettability of the binder on the ceramic phase, refines the ceramic phase, and strengthens the binder $[15,22,30]$. On the other hand, the TiC hard phase and added WC react during sintering to form $(\mathrm{Ti}, \mathrm{W}) \mathrm{C}$ rim structure on the surface of TiC particles and the rigidity of the hard phase increases because of the high rigidity of WC. Accordingly, the impact toughness of the TiC-and/or TiCN-based cermets increases due to WC addition if the thickness of the $(\mathrm{Ti}, \mathrm{W}) \mathrm{C}$ rim structure is appropriate. The transverse rupture strength and impact toughness of TiC- and/or TiCN-based cermets (TiC steel-bonded carbide included) are inferior to those of the conventional WC cemented carbide or WC steel-bonded carbide. One reason for this is the poor wettability of the binder on the ceramic phase. The intrinsic disadvantage of the low rigidity of $\mathrm{TiC}$ is also a possible reason for this inferiority.

Considering the practical application of the alloy, the ceramic particle size of the alloy should be increased adequately because big ceramic particles withstand stronger impact loads better than small ceramic particles. In practical application, a cellular structure is regarded as one big particle to undergo the external applied load. When the cracks occur and penetrate through a cellular structure, they penetrate preferably through the binder because of the fine $\mathrm{TiC}$ particles which consumes more energy to improves the toughness of the alloy. When the cracks spread into the coarse-grained TiC zone and encounter $\mathrm{TiC}$ particles, these large particles force the cracks to change the spreading direction and likely penetrate through the binder continually. Therefore, the binder of the alloy plays a dominant role in toughness improvement at the crack penetrating stage. However, at the fracture stage, the hard phase characteristics, particle shape and size of the alloy play the dominant roles. The toughness of the alloy is greatly improved because more $\mathrm{TiC}$ particles are split due to the bigger particle size and angular particle shape, as the rigidity of $\mathrm{TiC}$ is much higher than that of the binder, which consumes more energy during fracture.

In order to further investigate the strengthening mechanism on the TRS and IM improvement of the alloy, TEM analysis was carried out to examine whether the new phase formed in the binder because of Fe-Mo and Fe-Mo-Cr-C pre-alloyed powders were used as the binder.

Figure $6 \mathrm{~b}$ shows the TEM electron diffraction pattern analysis of the metallic binder of the coarse-grained TiC zone. The results show that the bonding phase was a single austenite structure, no other compounds were found, and it had a favorable metallurgical combination with TiC particles. Figure $6 c$,d shows the TEM bright image and electron diffraction pattern analysis of the metallic binder of the fine-grained TiC zone. The results show that the TiC particle size is about $1 \mu \mathrm{m}$, which is similar to the particle size of the raw materials, indicating that $\mathrm{TiC}$ particles undergo no significant change during the sintering process. The diffraction pattern of the bonding phase shows FCC (face centered cubic) structure, i.e., austenite, which is the same as the expected result. No other structural compounds were found in the bonding phase. The bonding interface between the binder and TiC particles is close, which shows that it has a good metallurgical bonding.

In this study, the content of Mn element is in the range of composition that makes Fe form a single austenite-like high manganese steel, while the content of $\mathrm{Mo}, \mathrm{Cr}$, $\mathrm{Ni}$ and other alloy elements is in the range of solid solution with the Fe element. Therefore, during the process of sintering or heat treatment, all alloy elements are completely in a solid solution in the bonding phase of the austenite structure. The single austenite phase has a high toughness while the solid solution strengthening of Mn, Mo, $\mathrm{Cr}$, Ni gives the bonding phase high strength and hardness. Thus, the TRS and IM improvement of the alloy are attributed to the uniform distribution of the alloying elements, refined grain structure. In particular, the IM improvement of the alloy is mainly attributed to the inhomogeneous structure of the alloy. Therefore, this is an instructive attempt to produce high impact toughness TiC-high Mn steel-bonded carbide. 

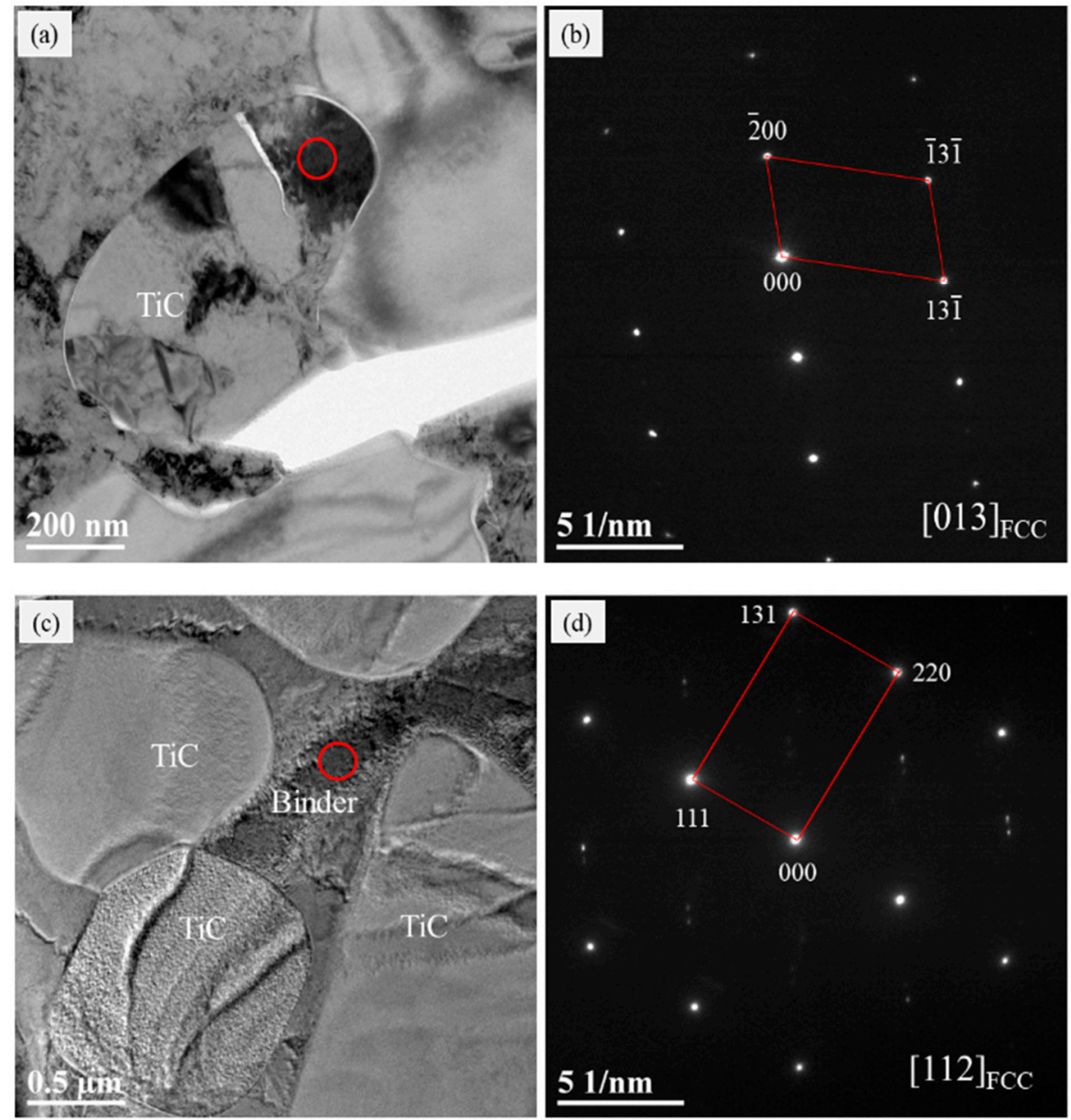

Figure 6. TEM electron diffraction pattern analysis of Sample \#2, (a) TEM image of coarse-grained TiC zone, (b) Electron diffraction pattern of binder marked by red circle in Figure 6a; (c) TEM image of fine-grained $\mathrm{TiC}$ zone, (d) Electron diffraction pattern of binder marked by the red circle in Figure 6c.

\section{Conclusions}

A cellular TiC-high Mn steel bonded carbide was designed and fabricated using powder metallurgy techniques. The main conclusions are as follows:

(1) A cellular structure consisting of fine-grained $\mathrm{TiC}$ zones distributed in the coarse-grained $\mathrm{TiC}$ ceramic matrix was obtained.

(2) The binder of the alloy is FCC (face centered cubic) high-Mn steel with good toughness, though $\mathrm{Fe}-\mathrm{Mo}$ and $\mathrm{Fe}-\mathrm{Mo}-\mathrm{Cr}-\mathrm{C}$ pre-alloyed powders were used as the binder of coarse-grained $\mathrm{TiC}$ zones and fine-grained $\mathrm{TiC}$ zones, respectively.

(3) When the starting ratio of MP-A to MP-B was 60:40, the alloy reached the maximum TRS and IM at $2231 \mathrm{MPa}$ and $12.87 \mathrm{~J} / \mathrm{cm}^{2}$, respectively. Thus, this paper provides a template for preparing high-strength and high-toughness TiC-high steel-bonded carbide.

Author Contributions: Conceptualization, G.L. and Y.P.; methodology, Y.P.; software, H.Y.; validation, G.L., H.Z. and H.Y.; formal analysis, M.H.; investigation, G.L.; resources, Y.P.; data curation, Y.P.; writing-original draft preparation, G.L.; writing-review and editing, F.L.; visualization, H.Z.; supervision, F.L.; project administration, M.H.; funding acquisition, G.L. All authors have read and agreed to the published version of the manuscript.

Funding: This research was funded by the Shandong Science and Technology Development Plan Project, grant number 2016GGX102044.

Acknowledgments: We would like to thank Editage (www.editage.cn) for English language editing. 
Conflicts of Interest: The authors declare that they have no conflict of interest.

\section{References}

1. Klaasen, H.; Kollo, L.; Kübarsepp, J. Mechanical properties and wear performance of compression sintered TiC based cermets. Powder Metall. 2007, 50, 132-136. [CrossRef]

2. Kübarsepp, J.; Reshetnyak, H.; Annuka, H. Characterization of the serviceability of steel-bonded hard metals. Int. J. Refract. Met. Hard Mater. 1993, 12, 341-348. [CrossRef]

3. Jam, A.; Nikzad, L.; Razavi, M. TiC-based Cermet Prepared by High-Energy Ball-Milling and Reactive Spark Plasma Sintering. Ceram. Int. 2017, 43, 2448-2455. [CrossRef]

4. Guo, L.; Hao, Y.; Ying, L.; Zhou, H.J.; Luo, F.H. Effect of Fe-Mo-Cr pre-alloyed powder on the microstructure and mechanical properties of TiC-high-Mn-steel cermet. Int. J. Refract. Met. Hard Mater. 2019. [CrossRef]

5. Boutefnouchet, H.; Curfs, C.; Triki, A.; Boutefnouchet, A.; Vrel, D. Self-propagating high-temperature synthesis mechanisms within the Ti-C-Ni system: A time resolved X-ray diffraction study. Powder Technol. 2012, 217, 443-450. [CrossRef]

6. Wang, Z.A.; Dai, H.Y.; Zou, Y. Effects of nano TiN addition on the microstructure and mechanical properties of TiC based steel bonded carbides. Rare Met. 2008, 27, 5-8. [CrossRef]

7. Worauaychai, N.; Poolthong, N.; Tongsri, R. Reduction of liquid phase formation temperature of TiC-Ni composite by sintering activator addition. Powder Technol. 2013, 246, 478-486. [CrossRef]

8. Jing, T.F.; Zhang, F.C. The work-hardening behavior of medium manganese steel under impact abrasive wear condition. Mater. Lett. 1997, 31, 275-279.

9. Wang, Z.; Lin, T.; He, X.; Shao, H.P.; Zheng, J.S.; Qu, X.H. Microstructure and properties of TiC-high manganese steel cermet prepared by different sintering processes. J. Alloy. Compd. 2015, 650, 918-924. [CrossRef]

10. Liu, N.; Xu, Y.; Li, Z.H.; Chen, M.H.; Li, G.H.; Zhang, L.D. Influence of molybdenum addition on the microstructure and mechanical properties of TiC-based cermets with nano-TiN modification. Ceram. Int. 2003, 29, 919-925. [CrossRef]

11. Wang, N.W.; Tong, W.Y.; Fang, M.X. Influence of Mo Content on the Properties of TiC-Based Cermets. Adv. Mater. Res. 2012, 602-604, 530-535. [CrossRef]

12. Li, Y.; Liu, N.; Zhang, X.B.; Rong, C.L. Effect of Mo addition on the microstructure and mechanical properties of ultra-fine grade TiC-TiN-WC-Mo ${ }_{2}$ C-Co cermets. Int. J. Refract. Met. H. 2008, 26, 190-196. [CrossRef]

13. Lin, N.; Wu, C.H.; He, Y.H.; Zhang, D.F. Effect of Mo and Co additions on the microstructure and properties of WC-TiC-Ni cemented carbides. Int. J. Refract. Met. Hard Mater. 2012, 30, 107-113. [CrossRef]

14. Zhou, S.; Zhao, W.; Xiong, W. Microstructure and properties of the cermets based on Ti(C,N). Int. J. Refract. Met. Hard Mater. 2009, 27, 26-32. [CrossRef]

15. Xiong, J.; Guo, Z.X.; Shen, B.L.; Cao, D. The effect of $\mathrm{WC}, \mathrm{Mo}_{2} \mathrm{C}, \mathrm{TaC}$ content on the microstructure and properties of ultra-fine TiC $0.7 \mathrm{~N} 0.3$ cermet. Mater. Design. 2007, 28, 1689-1694. [CrossRef]

16. Stewart, T.L.; Plucknett, K.P. The effects of $\mathrm{Mo}_{2} \mathrm{C}$ additions on the microstructure and sliding wear of TiC0.3N0.7-Ni3Al cermets. Int. J. Refract. Met. Hard Mater. 2015, 50, 227-239. [CrossRef]

17. Liu, C.; Lin, N.; He, Y.H. Influence of Mo2C and TaC additions on the microstructure and mechanical properties of $\mathrm{Ti}(\mathrm{C}, \mathrm{N})$-based cermets. Ceram. Int. 2016, 42, 3569-3574. [CrossRef]

18. Wan, W.C.; Xiong, J.; Li, Y.H.; Tang, Q.F.; Liang, M.X. Erosion-corrosion behavior of Ti(C,N)-based cermets containing different secondary carbides. Int. J. Refract. Met. Hard Mater. 2017, 66, 180-187. [CrossRef]

19. Shin, S.G.; Lee, J.H. Effect of carbide additions on grain growth in TiC-Ni cermets. Met. Mater. Int. 2006, 12, 57-62. [CrossRef]

20. Qu, J.; Xiong, W.H.; Ye, D.M.; Yao, Z.H.; Liu, W.J.; Lin, S.J. Effect of WC content on the microstructure and mechanical properties of Ti(C0.5N0.5)-WC-Mo-Ni cermets. Int. J. Refract. Met. Hard Mater. 2010, 28, $243-249$. [CrossRef]

21. Wang, J.; Liu, Y.; Zhang, P.; Peng, J.C.; Ye, J.W.; Tu, M.J. Effect of WC on the microstructure and mechanical properties in the $\mathrm{Ti}(\mathrm{C} 0.3 \times \mathrm{C}-(\mathrm{Co}, \mathrm{Ni})$ system. Int. J. Refract. Met. Hard Mater. 2009, 27, 9-13.

22. Dong, G.B.; Xiong, J.; Chen, J.Z.; Guo, Z.X.; Wan, W.C.; Yi, C.H.; Chen, H.S. Effect of WC on the microstructure and mechanical properties of nano Ti(C,N)-based cermets. Int. J. Refract. Met. Hard Mater. 2012, 35, 159-162. [CrossRef] 
23. Akhtar, F.; Humail, I.S.; Askari, S.J.; Tian, J.J.; Guo, S.J. Effect of WC particle size on the microstructure, mechanical properties and fracture behavior of WC-(W, Ti, Ta) C-6wt $\%$ Co cemented carbides. Int. J. Refract. Met. Hard Mater. 2007, 25, 405-410. [CrossRef]

24. Mun, S.; Kang, S. Effect of hafnium carbide on microstructure of titanium carbo-nitride-nickel cermets. Powder Metall. 1999, 42, 251-256. [CrossRef]

25. Li, G.; Yang, H.; Luo, F. Effect of Mo addition mode on the microstructure and mechanical properties of TiC-high Mn steel cermets. Ceram. Int. 2020, 46, 5745-5752. [CrossRef]

26. Fang, Z.; Lockwood, G.; Griffo, A. A dual composite of WC-Co. Metall. Mater. Trans. A 1999, 30, 3231-3238. [CrossRef]

27. Deng, X.; Patterson, B.R.; Chawla, K.K.; Koopman, M.C.; Fang, Z.; Lockwood, G.; Griffo, A. Mechanical properties of a hybrid cemented carbide composite. Int. J. Refract. Met. Hard Mater. 2001, 19, 547-552. [CrossRef]

28. Mari, D.; Bolognini, S.; Feusier, G.; Gutard, T.; Viatte, T.; Benoit, W. TiMoCN based cermets Part II. Microstructure and room temperature mechanical properties. Int. J. Refract. Met. Hard Mater. 2003, 21, 47-53. [CrossRef]

29. Liu, N.; Zeng, Q.M.; Huang, X.M. Microstructure in titanium carbonitride cermets. Mater. Sci. Technol. 2001, 17, 1050-1054. [CrossRef]

30. Wan, W.; Xiong, J.; Liang, M. Effects of secondary carbides on the microstructure, mechanical properties and erosive wear of Ti(C,N)-based cermets. Ceram. Int. 2017, 43, 944-952. [CrossRef]

(C) 2020 by the authors. Licensee MDPI, Basel, Switzerland. This article is an open access article distributed under the terms and conditions of the Creative Commons Attribution (CC BY) license (http://creativecommons.org/licenses/by/4.0/). 